Eventos 



\title{
Transtorno Dismófico MusculaR ${ }^{\star}$
}

\author{
Hugo Leonardo Rodrigues Soares $\star \star$ \\ Hérica Cristina Batista Gonçalves ${ }^{\star \star}$
}

Introdução: a Dismorfia Muscular é uma espécie de subdivisão de um quadro mais abrangente chamado de Transtorno Dismórfico Corporal, definido como uma preocupação com algum defeito imaginário na aparência física numa pessoa com aparência normal. A Dismorfia Muscular seria uma alteração na percepção do esquema corporal, específica da estética muscular do corpo e não um defeito na percepção corporal imaginário qualquer. Em 1993, Pope e colaboradores, analisando uma amostra de 108 fisiculturistas (com e sem uso de esteróides anabolizantes), descreveram o que foi denominado na época de anorexia nervosa reversa. Ao contrário dos Transtornos Dismórficos Corporais típicos, nos quais a preocupação principal é com áreas específicas, a dismorfia muscular envolve uma preocupação de não ser suficientemente forte e musculoso em todas as partes do corpo. Além disto, os indivíduos acometidos passam a ter uma importante limitação de atividades diárias, dedicando muitas horas a levantamento de peso e dietas para hipertrofia. O Transtorno Dismórfico Corporal é conceituado como um transtorno do espectro obsessivo-compulsivo a partir de evidências oriundas de estudos psicopatológicos, genéticos e terapêuticos que apontam diversas semelhanças com o Transtorno Obsessivo-Compulsivo (TOC). Por exemplo, ambos se caracterizam por pensamentos desagradáveis indesejados que conduzem a comportamentos compulsivos e repetitivos. Metodologia: Este trabalho se propôs a realizar uma revisão sobre o transtorno dismórfico muscular, quadro descrito inicialmente pelo psiquiatra Pope em 1993, sob a denominação de anorexia nervosa reversa. Resultados e conclusões: Pope e colaboradores descreveram a prevalência de $10 \%$ de dismorfia muscular entre levantadores de peso e de até $84 \%$ entre fisiculturistas que participavam de competições. Em relação à etiologia, aspectos socioculturais parecem desempenhar um papel fundamental na gênese da dismorfia muscular. A importância que a sociedade demonstra em relação à aparência física é notória na atualidade. È sabido que fatores ambientais têm influência na gênese dos transtornos alimentares. O mesmo parece ocorrer com a dismorfia muscular. Neste contexto, academias de ginástica parecem ser o ambiente ideal para encontrar indivíduos A alta prevalência de comorbidades entre os indivíduos com dismorfia muscular sugere que este quadro possa fazer parte de um grupo de sintomas com características em comum, como os transtornos

^ Trabalho apresentado na $29^{\text {a }}$ Semana Científica da Faculdade de Medicina da UFF, realizada em 30 de novembro e 1 de dezembro de 2006, no Hospital Universitário Antônio Pedro, Niterói, Rio de Janeiro.

$\star \star$ Médico formado pela Universidade Federal Fluminense. Pós-Graduando em Psicanálise e Saúde Mental pela UERJ. Ex-monitor das disciplinas de Neuropsiquiatria Infantil e Desenvolvimento Infantil. Especialista em Dependência Química pela UNIFESP/EPM. Especialista em Medicina do Esporte pela Universidade Veiga de Almeida. Pòs-Graduado (lato sensu) Políticas, Instituições e Saúde Mental e Vigilância Sanitária. Fiocruz/Ensp.

E-mail: hugolrsoares@yahoo.com.br

$\star \star \star$ Psicóloga, residente em Saúde Mental do Instituto Municipal Philippe Pinel.

E-mail: hericacris@yahoo.com.br 
alimentares, transtorno obsessivo- compulsivo e outros transtornos dismórficos corporais. Olivardia e colaboradores observaram que indivíduos freqüentadores de academias de ginástica que faziam levantamento de peso e tinham dismorfia muscular apresentavam maior prevalência de uso de esteróides anabolizantes do que os indivíduos nas mesmas condições sem o transtorno. Outro aspecto que merece ser apontado é que os indivíduos com uso destas drogas apresentam uma maior distorção de imagem corporal do que aqueles que não as utilizam.O Transtorno Dismórfico Corporal ainda recebe pouca atenção na rede assistencial e na literatura, estimando-se que apenas cerca de $10 \%$ recebam atendimento apropriado. Parece ser mais prevalente entre indivíduos do sexo masculino A dismorfia muscular está associada a sofrimento e prejuízos em várias áreas de funcionamento do individuo. Além disto, sua presença pode aumentar o risco de abuso de esteróides anabolizantes, drogas com conseqüências potencialmente perigosas. 